\title{
Potential use of buccal epithelium for genetic diagnosis of atherosclerosis using mtDNA mutations
}

\author{
Vasily V. Sinyov ${ }^{1}$, Margarita A. Sazonova ${ }^{1,2}$, Anastasia I. Ryzhkova ${ }^{2}$, Elena V. Galitsyna ${ }^{3}$, Alexsandra A. \\ Melnichenko ${ }^{2}$, Anton Y. Postnov ${ }^{1}$, Alexander N. Orekhov ${ }^{2,4}$, Andrey V. Grechko ${ }^{5}$, Igor A. Sobenin ${ }^{1,2}$ \\ ${ }^{1}$ Laboratory of Medical Genetics, Russian Cardiology Research and Production Complex, Moscow 121552, Russia. \\ ${ }^{2}$ Laboratory of Angiopathology, Institute of General Pathology and Pathophysiology, Moscow 125315, Russia. \\ ${ }^{3}$ Department of Genetics, Southern Federal University, Rostov-on-Don 344006, Russia. \\ ${ }^{4}$ Institute for Atherosclerosis Research, Skolkovo Innovative Centre, Moscow 121609, Russia. \\ ${ }^{5}$ Federal Scientific Clinical Center for Resuscitation and Rehabilitation, Moscow 109240, Russia.
}

Correspondence to: Dr. Vasily V. Sinyov, Laboratory of Medical Genetics, Russian Cardiology Research and Production Complex, 15a, 3rd Cherepkovskaya Street, Moscow 121552, Russia. E-mail: centaureaceanus@mail.ru

How to cite this article: Sinyov VV, Sazonova MA, Ryzhkova AI, Galitsyna EV, Melnichenko AA, Postnov AY, Orekhov AN, Grechko AV, Sobenin IA. Potential use of buccal epithelium for genetic diagnosis of atherosclerosis using mtDNA mutations. Vessel Plus 2017;1:145-50.

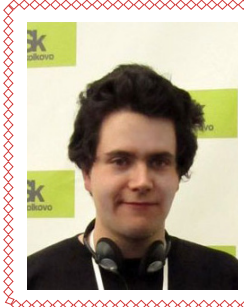

PhD student Vasily V. Sinyov is a junior research scientist in Laboratory of Medical Genetics, Russian Cardiology Research and Production Complex. He graduated from Moscow Agricultural Academy named after Timiryazev in 2010. He has worked in the group for the study of molecular-genetic mechanisms of atherogenesis in the Institute for Atherosclerosis Research, Skolkovo Innovation Centre. He has more than 20 publications which are dedicated to investigations of the association of mitochondrial genome mutations with cardiovascular diseases, and in particular with atherosclerosis.

\section{Article history:}

Received: 10 Oct 2016

Accepted: 6 Jan 2017

Published: 26 Sep 2017

\section{Key words:}

Buccal cell,

mutation,

mtDNA,

threshold heteroplasmy level, mitochondrial genome, atherosclerosis

\section{ABSTRACT}

Aim: The aim of this pilot study was to compare the heteroplasmy levels of specific mitochondrial (mt)DNA mutations in human buccal epithelial and whole blood cells in participants with different degrees of predisposition to atherosclerosis. The potential for buccal epithelium to be used for the genetic diagnosis of atherosclerosis using mtDNA mutations was assessed. Methods: Samples of buccal epithelial and whole blood cells were obtained from 134 donors. DNA was extracted from the samples and subjected to polymerase chain reaction and pyrosequencing. The threshold heteroplasmy levels of the mutations m.12315G $>$ A, m.3336T $>$ C, m.1555A $>$ G, m.13513G $>$ A, and m.3256C $>$ T were analyzed in order to assess the potential for using buccal epithelium and whole blood for the genetic diagnosis of atherosclerosis. Results: The threshold heteroplasmy levels of the assessed mitochondrial mutations did not significantly differ between buccal epithelial and whole blood cells. Conclusion: Buccal epithelial cells may be preferable to whole blood cells for analyzing the association of mitochondrial genome mutations with atherosclerosis.



This is an open access article licensed under the terms of Creative Commons Attribution 4.0 International License (https://creativecommons.org/licenses/by/4.0/), which permits unrestricted use, distribution, and reproduction in any medium, as long as the original author is credited and the new creations are licensed under the identical terms.

For reprints contact: service@oaepublish.com






\section{INTRODUCTION}

Investigations of the human genome make the early, presymptomatic diagnosis of different pathologies possible. According to the literature,,$^{[1-4]}$ various pathologies, including atherosclerosis, may be associated with mitochondrial mutations. The phenomenon of heteroplasmy is typical for the mitochondrial genome, meaning that a quantitative assessment of mutant alleles in the mitochondrial genome is necessary when investigating the association of mitochondrial mutations with diseases, in particular, the heteroplasmy level of mutations associated with pathologies should be evaluated.

Because of the instability of the mitochondrial genome, both somatic and hereditary mutations often occur. These can accumulate, influencing the phenotype of the carrier. According to the literature, heteroplasmy of the mitochondrial genome is common in normal human cells. ${ }^{[5]}$ During human embryogenesis, in the process of determining cells and tissues, morphologic and chemical differences occur between cells. As a result of cell division, mitochondria are randomly distributed between cells. This determines the difference between cells in the ratio of normal and mutant molecules of mitochondrial (mt)DNA. It has previously been established that single nucleotide polymorphisms of the mitochondrial genome are unevenly distributed in the tissues and organs of adults. ${ }^{[6-8]}$ This uneven distribution impedes the use of biomarkers in diagnosing different diseases. Therefore, the identification of biomarkers for the non-invasive genetic diagnosis of pathologies seems an interesting prospect.

The aim of the present pilot study was to compare heteroplasmy levels in mtDNA m.12315G $>A$, m.3336T $>C, \quad m .1555 A>G, \quad m .13513 G>A$, and m.3256C $>T$ between human buccal epithelial cells and whole blood cells in individuals with different degrees of predisposition to atherosclerosis. The potential use of buccal epithelium for the genetic diagnosis of atherosclerosis using mutations in mtDNA was assessed.

\section{METHODS}

This study was carried out according to the Declaration of Helsinki and with permission of an ethics committee (Russian Cardiology Research and Production Complex, Moscow, Russia). Samples were taken from 134 donors, all of whom provided a written informed consent.

Samples of buccal epithelial and whole blood cells were obtained from the donors.
High-resolution B-mode ultrasonography using a linear vascular transducer at $7.5 \mathrm{MHz}$ with the SonoScape SSI-1000 ultrasonic scanner (SonoScape Medical Corp., Shenzhen, China) was used to determine the degree of arterial stenosis of each participant. Intima-medial thickness (IMT) was measured using the program ProSound (R. Selzer, California Institute of Technology, Pasadena, USA). Ultrasonographic examination of the carotid arteries included scanning the left and right carotid arteries with a focus on the back wall of the artery in three fixed projections: anterolateral, lateral, and posterolateral. ${ }^{[9]}$

\section{DNA phenol-chloroform extraction}

Total DNA for this study was isolated from whole blood using phenol-chloroform extraction. ${ }^{[10,11]}$ This DNA isolation method included the following steps: (1) cell lysis (using sodium dodecyl sulfate); (2) enzymatic degradation of proteins with proteinase $\mathrm{K}$; (3) cell lysate deproteinization with phenol and chloroform.

The above-mentioned stages of pure DNA product isolation came amid centrifugation to remove denatured proteins and fragments of cell organelles.

Next, DNA was precipitated from the solution using ethanol and, following centrifugation, the precipitate was dissolved in a buffer solution.

\section{Polymerase chain reaction}

Polymerase chain reaction (PCR) was conducted with the aim of amplifying the short-chain mtDNA fragments to achieve a sufficient number of amplicon copies for further analysis of these fragments. The conditions for PCR were mentioned in previous publications..$^{[4,10-12]}$

\section{Pyrosequencing}

Short-chain amplicons obtained during PCR were subjected to pyrosequencing in order to determine the nucleotide sequences of these fragments and assess heteroplasmy levels in the investigated mtDNA positions. This work was performed using the PSQ96MA pyrosequencer (Biotage AB, Uppsala, Sweden), as previously described. ${ }^{[13]}$

\section{Analysis of heteroplasmy levels in mtDNA mutations}

Quantitative assessment of the mutant allele involved estimating the heteroplasmy levels of mtDNA mutations, using the pyrogram peak height of each sample in the studied region of a single-stranded PCR fragment of mitochondrial genome. The general formula for calculating the percentage of heteroplasmy was as follows: ${ }^{[10,11]}$ 


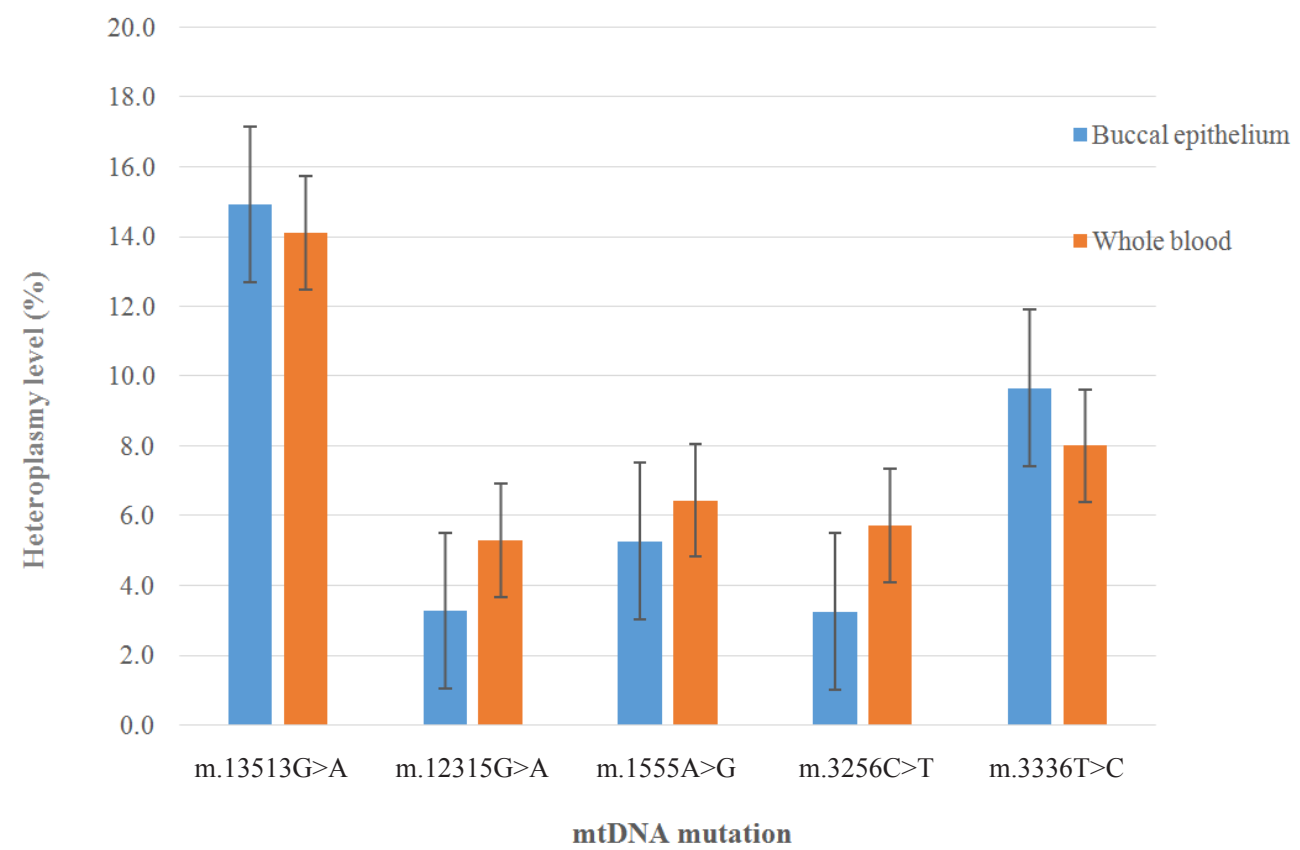

Figure 1: The heteroplasmy level of mitochondrial genome mutations in whole blood and buccal epithelium from 134 donors. Error bars show the standard error. mtDNA: mitochondrial DNA

$$
P=[(h-N) /(M-N)]^{*} 100 \%
$$

Where: $P$ is the percentage heteroplasmy; $h$ is the peak height of the investigated nucleotide; $N$ is the peak height of the investigated nucleotide, relevant to the presence of $100 \%$ of normal alleles in a sample; $M$ is the peak height of the investigated nucleotide, relevant to the presence of $100 \%$ of mutant alleles in a sample.

Statistical processing of the data was carried out using the software package SPSS version 22.0 (SPSS Inc., USA). ${ }^{[14]}$ Independent samples were assessed using $t$-tests and Mann-Whitney $U$-tests, and correlation analyses were also conducted. Differences were considered significant at $P<0.05$.

Next, the possibility that buccal epithelium might be equivalent to whole blood for the genetic diagnosis of atherosclerosis was assessed. For this purpose the threshold heteroplasmy level of mutations was used, after which in individuals atherosclerotic plaques were detected or antiatherogenic effect of these single nucleotide substitutions manifests. ${ }^{[14]}$ According to the data, previously obtained by the members of our laboratory, ${ }^{[11]}$ the threshold heteroplasmy level of mtDNA mutations for atherosclerotic plaques in human carotid arteries for atherogenic mutations is: $17.5 \%$ for $m .1555 \mathrm{~A}>\mathrm{G} ; 6.5 \%$ for $\mathrm{m} .3336 \mathrm{~T}>\mathrm{C} ; 7.5 \%$ for m.12315G $>A$; and $15.5 \%$ for $m .3256 C>T$. For the antiatherogenic mutation $\mathrm{m} .13513 \mathrm{G}>\mathrm{A}$, the threshold level of heteroplasmy is $32.5 \%$.

\section{RESULTS}

The investigated sample of 134 participants was divided by gender and age. All the examined individuals had their IMT measured. A total of 35 of the donors were men, with a mean \pm standard deviation (SD) age of $61 \pm 10$ years and an IMT of $0.84 \pm 0.21 \mathrm{~mm}$. The remaining 97 donors were women, with a mean \pm SD age of $61 \pm 11$ years and an IMT of $0.79 \pm 0.41 \mathrm{~mm}$.

During the quantitative assessment of the mutant allele of mitochondrial genome, data on the heteroplasmy levels in buccal epithelial and whole blood cells were obtained [Figure 1]. The obtained data were analyzed using the $t$-test for independent samples.

Significant differences in the heteroplasmy level of the mitochondrial genome mutation $\mathrm{m} .3256 \mathrm{C}>\mathrm{T}$ were found between buccal epithelial and whole blood cells $(P=0.01)$. However, there were no differences in the mutations $\mathrm{m} .13513 \mathrm{G}>\mathrm{A}(P=0.48), \mathrm{m} .3336 \mathrm{~T}>\mathrm{C}(P=$ 0.65), m.12315G $>\mathrm{A}(P=0.13)$, and $\mathrm{m} .1555 \mathrm{~A}>\mathrm{G}(P=$ $0.23)$.

The difference between average heteroplasmy levels of the investigated mutations did not exceed $5 \%$ and the standard error in a range of cases was higher than the mean level. This is probably connected to the fact that each individual has a different heteroplasmy level of mtDNA mutations, and that heteroplasmy levels significantly differ within an investigated sample. Therefore, it is unlikely that the impact of the 
Table 1: Significance of rank differences in heteroplasmy levels between human buccal epithelium and whole blood

\begin{tabular}{lccccc}
\hline & $\mathbf{m . 1 2 3 1 5 G}>\mathbf{A}$ & $\mathbf{m . 1 3 5 1 3 G}>\mathbf{A}$ & $\mathbf{m . 1 5 5 5 A}>\mathbf{G}$ & m.3256C $>$ T & m.3336T>C \\
\hline Mann-Whitney U-test & 8,167 & 7,761 & 7,625 & 6,554 & 595 \\
$P$ value & 0.20 & 0.18 & 0.36 & 0.08 & 0.80 \\
\hline
\end{tabular}

Table 2: Ranking of atherosclerotic plaques in the lumen of blood vessels of the brachiocephalic bed, depending on the degree of stenosis

\begin{tabular}{cc}
\hline Atherosclerotic plaque size (points) & Degree of stenosis (\%) \\
\hline 0 & 0 \\
1 & $<20$ \\
2 & $20-40$ \\
3 & $>40$ \\
\hline
\end{tabular}

heteroplasmy level of mitochondrial genome mutations on different human diseases can be evaluated using the percentage expression of mutational burden. To determine the difference in heteroplasmy levels among samples, it is necessary to convert heteroplasmy levels into rank values using the threshold value of heteroplasmy percentage. It should be noted that, despite the fact that the average heteroplasmy level for a number of mutations was much lower than the threshold level (e.g. for mutation m.13513G>A, the threshold heteroplasmy level was $32.5 \%$ while the average value of this parameter for the buccal epithelium and whole blood was $15 \%$ and $14 \%$, respectively), some individuals had heteroplasmy levels above the threshold level.

After ranking the heteroplasmy levels, differences in the mutational burden distribution in buccal epithelium and whole blood were determined using the Mann-Whitney U-test [Table 1]. As can be seen in Table 1, the threshold heteroplasmy level of the mutations m.12315G>A, m.13513G>A, m.1555A>G, m.3256C $>\mathrm{T}$, and m.3336T $>\mathrm{C}$, which are associated with atherosclerotic plaques, did not significantly differ between the buccal epithelium and whole blood.

Consequently, DNA samples from both the buccal epithelium and the whole blood may be of use for the molecular genetic diagnosis of atherosclerosis using mitochondrial genome mutations associated with this disease.

To check the distribution of heteroplasmy values in different cell types and their association with gender, age, the degree of angiostenosis, and IMT, a correlation analysis of heteroplasmy levels in the buccal epithelium and whole blood was carried out. The parametric variables of age and IMT were compared with the average heteroplasmy levels of the mitochondrial genome mutations m.12315G>A, m.13513G $>A$, m.1555A $>$ G, m.3256C $>T$, and m.3336T $>C$, while the non-parametric variables of atherosclerotic plaques and gender were compared with threshold heteroplasmy level distributions. Variability was assessed according to the available data on the size of an atherosclerotic plaque (in points) [Table 2].

A correlation analysis was performed between the threshold levels of heteroplasmy in the mitochondrial genome mutations m.12315G $>A, m .13513 \mathrm{G}>\mathrm{A}$, $m .1555 A>G, m .3256 C>T$, and $m .3336 T>C$ in the buccal epithelium and whole blood, and the atherosclerotic plaque size, IMT, age, and gender of individuals from the investigated sample [Tables 3 and 4]. The differences were considered significant at $95 \%$ probability of faultless prognosis. These analyses found that the heteroplasmy level of mutation m.1555A>G in the buccal epithelium was significantly positively correlated with IMT and negatively correlated with age [Table 3]. In whole blood, the heteroplasmy level of mutation m.1555A $>G$ was significantly positively correlated with IMT, similar to the correlation in the buccal epithelium.

\section{DISCUSSION}

A range of scientific publications have indicated that mitochondrial genome mutations, which are associated

Table 3: Correlation of heteroplasmy level of mtDNA mutations in human buccal epithelium with plaques, IMT, gender, and age

\begin{tabular}{|c|c|c|c|c|c|c|}
\hline \multicolumn{2}{|c|}{ Variable } & \multirow{2}{*}{$\begin{array}{c}\mathrm{m} .13513 \mathrm{G}>\mathrm{A} \\
0.09\end{array}$} & \multirow{2}{*}{$\begin{array}{c}\mathrm{m} .12315 \mathrm{G}>\mathrm{A} \\
0.03\end{array}$} & \multirow{2}{*}{$\begin{array}{c}\mathrm{m} .1555 A>G \\
-0.11\end{array}$} & \multirow{2}{*}{$\begin{array}{c}\mathrm{m} .3256 \mathrm{C}>\mathrm{T} \\
-0.12\end{array}$} & \multirow{2}{*}{$\begin{array}{c}\mathrm{m} .3336 \mathrm{~T}>\mathrm{C} \\
-0.02\end{array}$} \\
\hline Plaque & Spearman correlation coefficient & & & & & \\
\hline & $P$ value & 0.31 & 0.78 & 0.22 & 0.19 & 0.81 \\
\hline \multirow[t]{2}{*}{ Gender } & Spearman correlation coefficient & 0.02 & -0.02 & 0.15 & -0.16 & -0.10 \\
\hline & $P$ value & 0.87 & 0.79 & 0.10 & 0.10 & 0.33 \\
\hline \multirow[t]{2}{*}{ Age } & Pearson correlation coefficient & -0.07 & -0.13 & $-0.33^{*}$ & -0.21 & -0.06 \\
\hline & $P$ value & 0.40 & 0.16 & 0.01 & 0.20 & 0.56 \\
\hline \multirow[t]{2}{*}{ IMT } & Pearson correlation coefficient & -0.07 & 0.14 & $0.53^{*}$ & 0.04 & -0.05 \\
\hline & $P$ value & 0.40 & 0.12 & 0.01 & 0.67 & 0.61 \\
\hline
\end{tabular}

*Highly significant. mtDNA: mitochondrial DNA; IMT: intima-medial thickness 
Table 4: Correlation of heteroplasmy level of mtDNA mutations in human whole blood with plaques, IMT, gender, and age

\begin{tabular}{|c|c|c|c|c|c|c|}
\hline \multicolumn{2}{|l|}{ Variable } & \multirow{2}{*}{$\begin{array}{c}\mathrm{m} .13513 \mathrm{G}>\mathrm{A} \\
-0.01\end{array}$} & \multirow{2}{*}{$\begin{array}{c}\text { m.12315G }>A \\
-0.08\end{array}$} & \multirow{2}{*}{$\begin{array}{c}\mathrm{m} .1555 \mathrm{~A}>\mathrm{G} \\
0.04\end{array}$} & \multirow{2}{*}{$\begin{array}{c}\mathrm{m} .3256 \mathrm{C}>\mathrm{T} \\
-0.02\end{array}$} & \multirow{2}{*}{$\begin{array}{c}\text { m.3336T }>C \\
-0.08\end{array}$} \\
\hline Plaque & Spearman correlation coefficient & & & & & \\
\hline & $P$ value & 0.89 & 0.37 & 0.66 & 0.82 & 0.42 \\
\hline \multirow[t]{2}{*}{ Gender } & Spearman correlation coefficient & 0.10 & -0.11 & 0.11 & 0.10 & -0.10 \\
\hline & $P$ value & 0.29 & 0.21 & 0.22 & 0.30 & 0.32 \\
\hline \multirow[t]{2}{*}{ Age } & Pearson correlation coefficient & 0.04 & 0.08 & -0.07 & -0.11 & 0.03 \\
\hline & $P$ value & 0.68 & 0.34 & 0.43 & 0.25 & 0.79 \\
\hline \multirow[t]{2}{*}{ IMT } & Pearson correlation coefficient & 0.35 & 0.05 & $0.26^{*}$ & 0.07 & -0.01 \\
\hline & $P$ value & 0.10 & 0.56 & 0.01 & 0.49 & 0.91 \\
\hline
\end{tabular}

*Highly significant. mtDNA: mitochondrial DNA; IMT: intima-medial thickness

with several human diseases, can be unequally distributed in tissues and organs. ${ }^{[15,16]}$ This has been shown in research with both healthy participants and those affected by disease. ${ }^{[17,18]}$ Therefore, we studied the heteroplasmy levels of the mutations m.12315G>A, m.13513G>A, m.1555A>G, m.3256C>T, and m.3336T $>C$, which have been associated with atherosclerosis, and the distribution of these mutations in different tissues and organs. To compare different cells and tissues, we used the parameter of the threshold heteroplasmy level of mutations. This enabled us to calculate average differences in heteroplasmy levels among samples from various participants. This parameter was calculated on the basis of the correlation between mtDNA mutations and the degree of atherosclerosis of the arterial vessel wall. ${ }^{[9]}$ The results indicate the absence of significant differences in threshold heteroplasmy levels of the mitochondrial genome mutations m.12315G $>A, m .13513 G>A$, m.1555A $>$ G, m.3256C $>$ T, and m.3336T $>C$ between human buccal epithelium and whole blood. In addition, we studied the variability of heteroplasmy levels in the same mutations in participants with different IMTs and different degrees of luminal occlusion. No correlation between the heteroplasmy level of mtDNA mutations and atherosclerotic plaque size was found. This may indicate an insufficient sample size to identify such a relationship. However, a significant direct correlation of mutation m.1555A>G with IMT was detected for DNA samples from both the buccal epithelium and whole blood. In line with previous research, ${ }^{[16,19-21]}$ we found no correlation between the level of mutational burden and either gender or age, apart from an inverse correlation of mutation m.1555A $>\mathrm{G}$ with age in buccal epithelial samples.

It is possible that the data on mutation m.1555A>G indicate that individuals with a high heteroplasmy level of this mutation may have a higher IMT than their peers with lower heteroplasmy levels. It is important to note that mutation $\mathrm{m} .1555 \mathrm{~A}>\mathrm{G}$ is localized in the gene of subunit $12 \mathrm{~S}$ of the mitochondrial genome. The association of this mutation with increased IMT may suggest that defects in mitochondrial ribosomes can lead to a decrease in the protein chains of respiratory enzymes. This might result in decreased ATP synthesis in cells, leading to oxidative stress and the unlimited proliferation of mutant cells. Such a process might culminate in increased IMT in the carotid arteries and the formation of atherosclerotic plaques (i.e. atherosclerosis).

In conclusion, the buccal epithelium and whole blood are quite common subjects of investigation in medicine, in particular in the genetic diagnosis of various human diseases. The data obtained during the present study suggest that DNA samples from either the buccal epithelium or whole blood can be used to determine the heteroplasmy levels of the mitochondrial genome mutations m.12315G $>A, m .13513 G>A$, m.1555A>G, m.3256C $>$ T, and m.3336T $>C$, which have been associated with atherosclerosis. It should be emphasized that buccal epithelial samples are far easier to collect, making this a preferable tissue for studying the association of mitochondrial genome mutations with atherosclerosis and the search for new biomarkers.

These findings will be of particular interest to specialists in medical genetics and medical practitioners.

\section{Authors' contributions}

Manuscript's conception and writing: V.V. Sinyov, M.A. Sazonova, A.Y. Postnov, A.N. Orekhov

Data base fulfillment: V.V. Sinyov, M.A. Sazonova, A.I. Ryzhkova, E.V. Galitsyna, A.A. Melnichenko

Manuscript's revision: A.V. Grechko, I.A. Sobenin

\section{Financial support and sponsorship}

This study was supported by the Russian Science Foundation (grant \#14-14-01038).

\section{Conflicts of interest}

The authors declare that the research was conducted in the absence of any commercial or financial 
relationships that could be construed as a potential conflict of interest.

\section{Patient consent}

All of the participants completed signed consent forms.

\section{Ethics approval}

This study was carried out according to the Declaration of Helsinki and with permission of an ethics committee (Russian Cardiology Research and Production Complex, Moscow, Russia).

\section{REFERENCES}

1. Sazonova MA, Budnikov YY, Khasanova ZB, Anton P, Sobenin IA, Orekhov A. Direct quantitative assessment of mutant allele in mitochondrial genome in atherosclerotic lesion of human aorta. Atheroscler Suppl 2007;8:45-6.

2. Postnov AY, Sazonova MA, Budnikov YY, Khazanova ZB, Sobenin IA, Orekhov AN. PO5-116 Association of somatic mitochondrial mutations with atherosclerosis. Atheroscler Suppl 2007;8:46.

3. Sobenin IA, Sazonova MA, Ivanova MM, Zhelankin AV, Myasoedova VA, Postnov AY, Nurbaev SD, Bobryshev YV, Orekhov AN. Mutation C3256T of mitochondrial genome in white blood cells: novel genetic marker of atherosclerosis and coronary heart disease. PLoS One 2012;7:e46573.

4. Sobenin IA, Sazonova MA, Postnov AY, Bobryshev YV, Orekhov AN. Mitochondrial mutations are associated with atherosclerotic lesions in the human aorta. Clin Dev Immunol 2012;2012:832464.

5. Li H, Liu D, Lu J, Bai Y. Physiology and pathophysiology of mitochondrial DNA. Adv Exp Med Biol 2012;942:39-51.

6. de Laat P, Koene S, van den Heuvel LP, Rodenburg RJ, Janssen MC, Smeitink JA. Clinical features and heteroplasmy in blood, urine and saliva in 34 Dutch families carrying the m.3243A $>\mathrm{G}$ mutation. $J$ Inherit Metab Dis 2012;35:1059-69.

7. Naue J, Hörer S, Sänger T, Strobl C, Hatzer-Grubwieser P, Parson $\mathrm{W}$, Lutz-Bonengel S. Evidence for frequent and tissue-specific sequence heteroplasmy in human mitochondrial DNA. Mitochondrion 2015;20:82-94.

8. Chinnery PF, Zwijnenburg PJ, Walker M, Howell N, Taylor RW, Lightowlers RN, Bindoff L, Turnbull DM. Nonrandom tissue distribution of mutant mtDNA. Am J Med Genet 1999;85:498-501.

9. Miasoedova VA, Kirichenko TV, Orekhova VA, Sobenin IA,
Mukhamedova NM, Martirosian DM, Karagodin VP, Orekhov AN. Study of intima-medial thickness (IMT) of the carotid arteries as an indicator of natural atherosclerosis progress in Moscow population. Patol Fiziol Eksp Ter 2012;(3):104-8. (in Russian)

10. Sazonova MA, Orekhov AN, Sobenin IA. Mitochondrial genome defects andatherosclerosis. Role of mitochondrial genome pathologies in atherosclerotic lesionsformation of an arterial wall. Palmarium Academic Publishing; 2014. (in Russian)

11. Sazonova M, Budnikov E, Khasanova Z, Sobenin I, Postnov A, Orekhov A. Studies of the human aortic intima by a direct quantitative assay of mutant alleles in the mitochondrial genome. Atherosclerosis 2009;204:184-90.

12. Sazonova MA, Sinyov VV, Barinova VA, Ryzhkova AI, Zhelankin AV, Postnov AY, Sobenin IA, Bobryshev YV, Orekhov AN. Mosaicism of mitochondrial genetic variation in atherosclerotic lesions of the human aorta. Biomed Res Int 2015;2015:825468.

13. Alderborn A, Kristofferson A, Hammerling U. Determination of single-nucleotide polymorphisms by real-time pyrophosphate DNA sequencing. Genome Res 2000;10:1249-58.

14. IBM Analytics. IBM SPSS. Available from: http://www.ibm.com/ analytics/us/en/technology/spss/spss-trials.html\#spss-trials\%20n.d. [Last accessed on Jan 17, 2017]

15. Wallace DC, Brown MD, Lott MT. Mitochondrial DNA variation in human evolution and disease. Gene 1999;238:211-30.

16. Frederiksen AL, Andersen PH, Kyvik KO, Jeppesen TD, Vissing J, Schwartz M. Tissue specific distribution of the 3243A- $>$ G mtDNA mutation. J Med Genet 2006;43:671-7.

17. Litvinova NA, Voronkova AS, Nikolaeva EA, Sukhorukov VS Tissue-specific features of mitochondrial DNA polymorphisms. Russian Bull Perinatol Pediatr 2015;60:76-8. (in Russian)

18. Pyle A, Taylor RW, Durham SE, Deschauer M, Schaefer AM, Samuels DC, Chinnery PF. Depletion of mitochondrial DNA in leucocytes harbouring the $3243 \mathrm{~A}->\mathrm{G}$ mtDNA mutation. $J$ Med Genet 2007;44:69-74.

19. Spyropoulos A, Manford M, Horvath R, Alston CL, Yu-Wai-Man P, He L, Taylor RW, Chinnery PF. Near-identical segregation of mtDNA heteroplasmy in blood, muscle, urinary epithelium, and hair follicles in twins with optic atrophy, ptosis, and intractable epilepsy. JAMA Neurol 2013;70:1552-5.

20. Lee HY, Chung U, Park MJ, Yoo JE, Han GR, Shin KJ. Differential distribution of human mitochondrial DNA in somatic tissues and hairs. Ann Hum Genet 2006;70:59-65.

21. Roberts KA, Calloway C. Characterization of mitochondrial DNA sequence heteroplasmy in blood tissue and hair as a function of hair morphology. J Forensic Sci 2011;56:46-60. 